\title{
Supplementary Material: How Well do Models Represent the Development of Extra-Tropical Cyclones? Evaluation of Two General Circulation Models Against NAWDEX IOP 6 Observations.
}

David L. A. Flack ${ }^{1 *}$, Gwendal Rivière ${ }^{1}$, Ionela Musat ${ }^{1}$, Romain Roehrig $^{2}$, Sandrine Bony ${ }^{1}$, Julien Delano: ${ }^{3}$, Quitterie Cazenave ${ }^{3}$, and Jacques Pelon ${ }^{3}$

${ }^{1}$ Laboratoire de Météorologie Dynamique/IPSL, Ecole Normale Supérieure, PSL Research University, Sorbonne University, École Polytechnique, IP Paris, CNRS, Paris, France

${ }^{2}$ CNRM, Université de Toulouse, Météo-France, CNRS, Toulouse, France

${ }^{3}$ LATMOS-IPSL, CNRS/INSU, University of Versailles, Guyancourt, France

Correspondence: Gwendal Rivière (griviere@lmd.ens.fr)

a) ARPEGE-HR (Total)

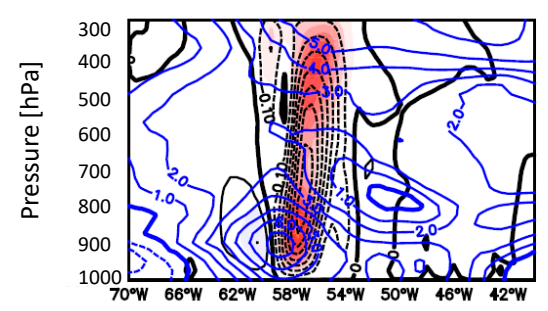

d) LMDZ-HR (Total)

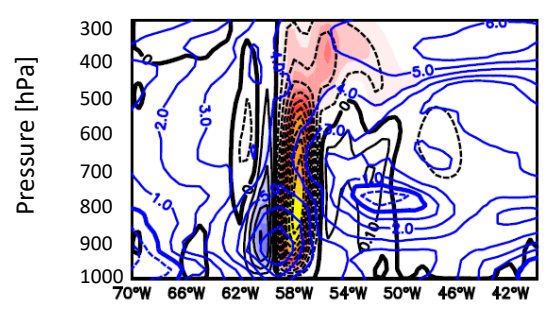

b) ARPEGE-HR (Dynamic)

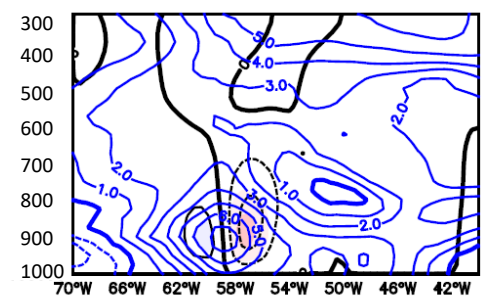

e) LMDZ-HR (Dynamic)

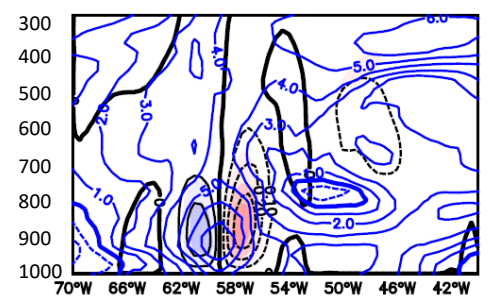

c) ARPEGE-HR (Diabatic)

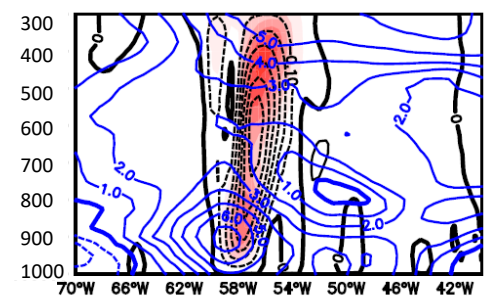

f) LMDZ-HR (Diabatic)

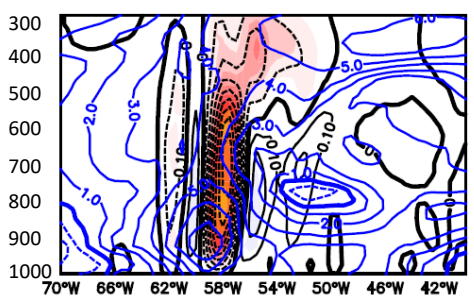

Figure S 1. A vertical cross-section averaged across the southern precursor in the HR hindcasts at 18 UTC 29 Septmeber 2016 (T+18 h). The baroclinic conversion (shaded), potential temperature anomaly (blue contours) and inverted $\omega$ (black contours) for a,d)total baroclinic conversion; $b, e)$ the baroclinic conversion due to dynamic processes only; and $c, f)$ the baroclinic conversion from diabatic processes. a-c) ARPEGE-HR and d-f) LMDZ-HR.

*Current Affiliation: Met Office, Exeter, UK 


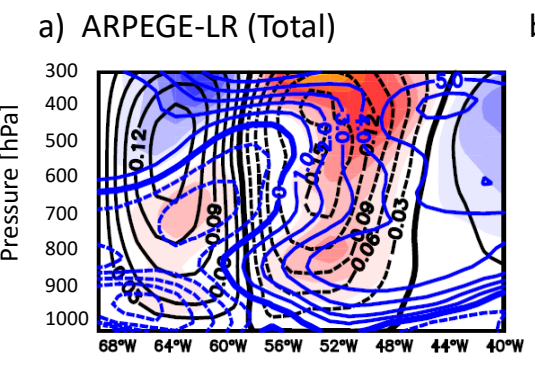

b) ARPEGE-LR (Dynamic)

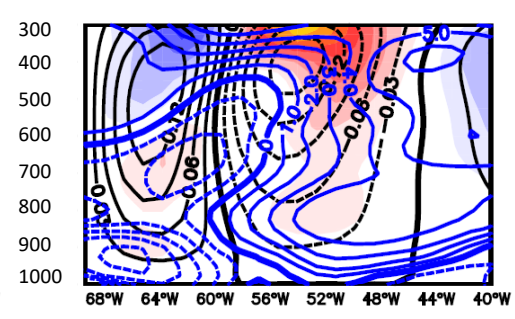

c) ARPEGE-LR (Diabatic)

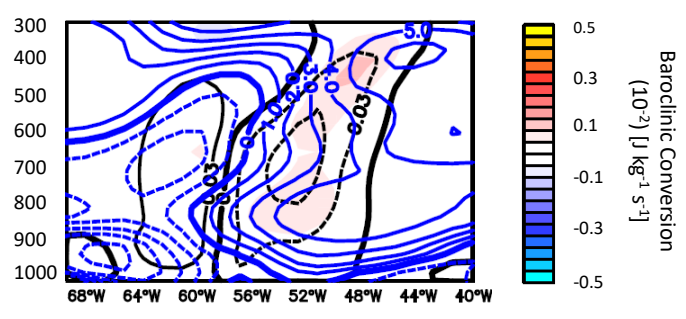

f) ARPEGE-HR (Diabatic)

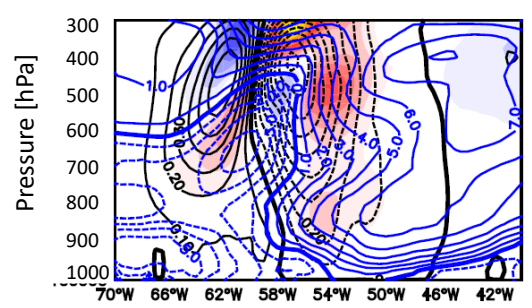

e) ARPEGE-HR (Dynamic)

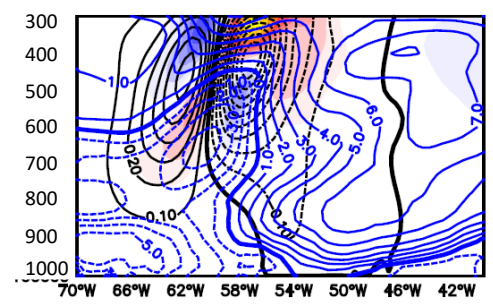

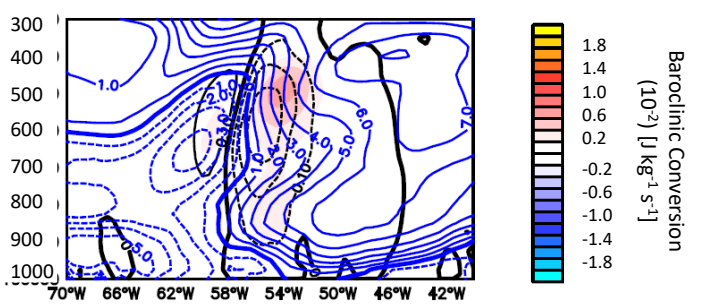

Figure S 2. A vertical cross-section averaged across the northern precursor in the ARPEGE hindcasts at 18 UTC 29 Septmeber 2016 (T+18 h). The baroclinic conversion (shaded), potential temperature anomaly (blue contours) and inverted $\omega$ (black contours) for a,d)total baroclinic conversion; $b, e)$ the baroclinic conversion due to dynamic processes only; and $c, f$ ) the baroclinic conversion from diabatic processes. a-c) ARPEGE-LR and d-f) ARPEGE-HR.

Table S 1. Ratios of super-cooled liquid water, mixed phase and ice in the observations, ARPEGE-LR, ARPEGE-HR, LMDZ-LR and LMDZ-HR for F6. The flight occurred from 09:00-11:00 UTC 2 October 2016 and the models are averages from 09:00 UTC and 12:00 UTC 2 October $2016(\mathrm{~T}+33 \mathrm{~h}$ and $\mathrm{T}+36 \mathrm{~h}$, respectively). Where LWC is liquid water content, "MAX"=ice+snow+liquid, Combined super-cooled liquid $=$ super-cooled liquid + mixed phase, and Combined ice $=$ ice + mixed phase .

\begin{tabular}{lccccc}
\hline & $\begin{array}{c}\text { Observations } \\
{[\%]}\end{array}$ & $\begin{array}{c}\text { LMDZ-LR } \\
{[\%]}\end{array}$ & $\begin{array}{c}\text { LMDZ-HR } \\
{[\%]}\end{array}$ & $\begin{array}{c}\text { ARPEGE-LR } \\
{[\%]}\end{array}$ & $\begin{array}{c}\text { ARPEGE-HR } \\
{[\%]}\end{array}$ \\
\hline $\begin{array}{l}\text { Super-cooled liquid } \\
\text { (LWC > 0.99(“MAX")) }\end{array}$ & 1.0 & 0.0 & 2.2 & 0.0 & 0.0 \\
$\begin{array}{l}\text { Mixed phase } \\
(0.01 \text { "MAX") < LWC < 0.99“MAX")) }\end{array}$ & 0.1 & 82.7 & 80.3 & 33.2 & 35.8 \\
Ice & 98.9 & 17.3 & 17.5 & 66.8 & 64.2 \\
(LWC < 0.01(“MAX")) & & & & & \\
Combined super-cooled liquid & 1.1 & 82.7 & 82.5 & 33.2 & 35.8 \\
Combined ice & 99.0 & 100.0 & 97.8 & 100.0 & 100.0 \\
\hline
\end{tabular}


a) ARPEGE-LR

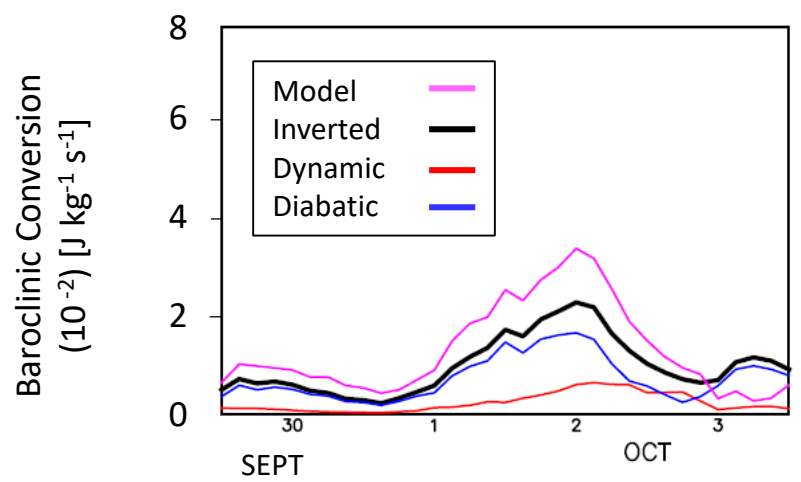

c) LMDZ-LR

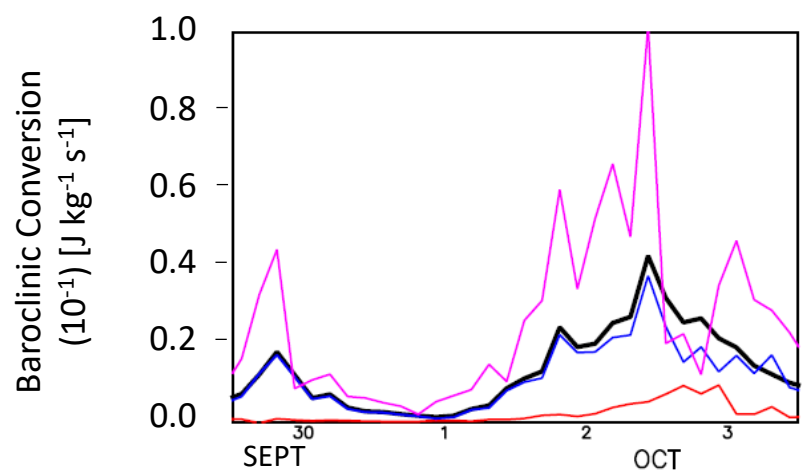

b) ARPEGE-HR

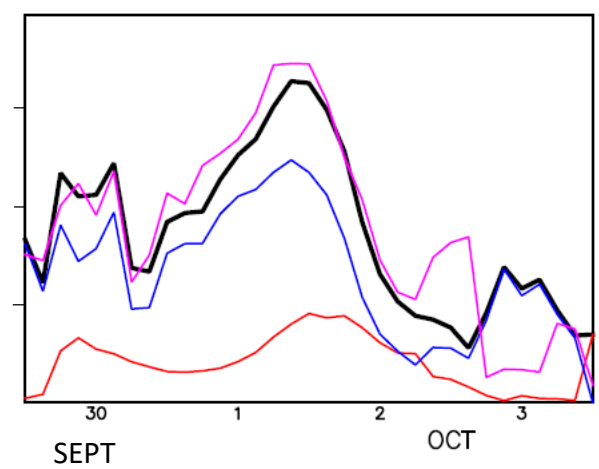

d) LMDZ-HR

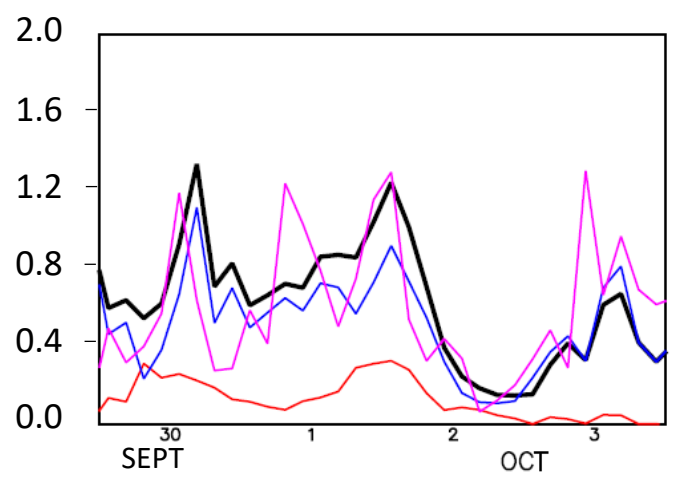

Figure S 3. The evolution of the baroclinic conversion at the point of maximum baroclinic conversion closest to the pressure minimum of the Stalactite Cyclone. the purple line is using the model $\omega$, the black line uses the inverted $\omega$, the red line uses the inverted $\omega$ from dynamic processes, and the blue line uses the inverted $\omega$ from diabatic processes. a) ARPEGE-LR; b) ARPEGE-HR; c) LMDZ-LR; and d) LMDZ-HR. All hindcasts were initated at 00 UTC 29 September 2016. 


\section{a) LMDZ-LR}

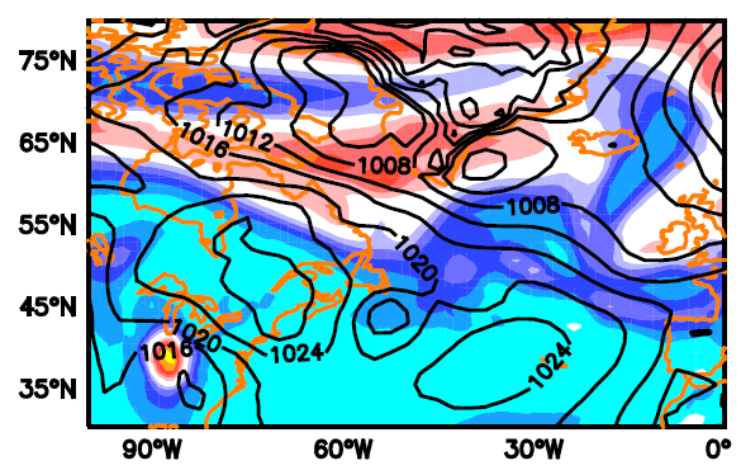

c) LMDZ-LR

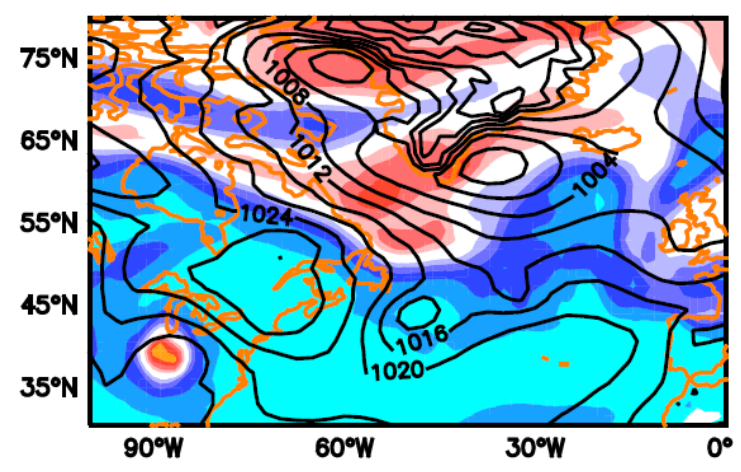

b) LMDZ-HR

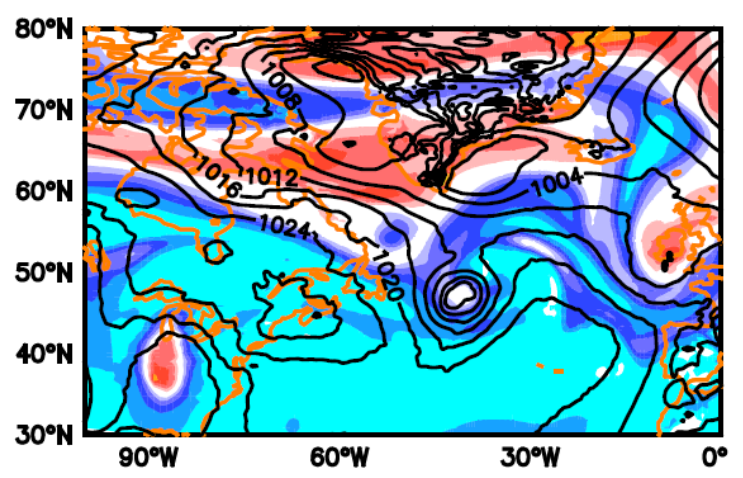

d) LMDZ-HR

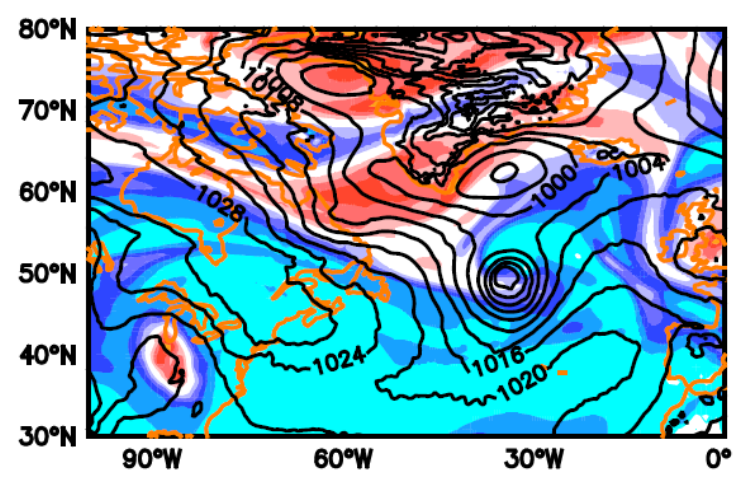

12 10

8

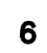

4

2

0

PV [PVU]

Figure S 4. The Potential Vorticity (PV; shaded) at $250 \mathrm{hPa}$ and mean sea level pressure (contoured) for LMDZ at the mature stage, during maximum deepening of the Stalactite Cyclone. The hindcasts are initated from 00 UTC 29 September 2016. a-b) 00 UTC 1 October 2016 (T+48 h); c-d) 12 UTC 1 October 2016 (T+60 h); a,c) LMDZ-LR; and b,d) LMDZ-HR. The colourscale applied to all panels. 
a) RASTA

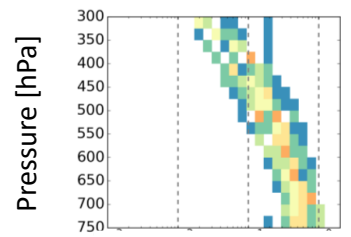

\section{f) RALI}

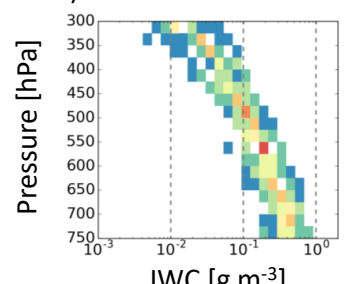

b) ARPEGE-LR

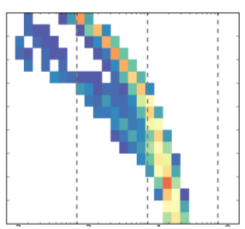

g) ARPEGE-LR
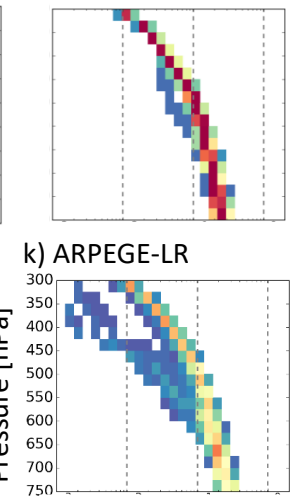

o) ARPEGE-LR

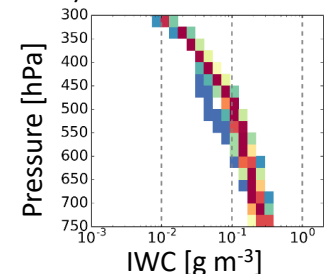

c) ARPEGE-HR

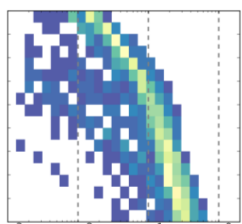

h) ARPEGE-HR

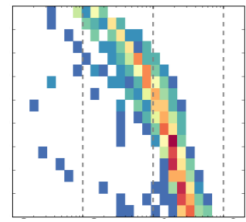

I) ARPEGE-HR

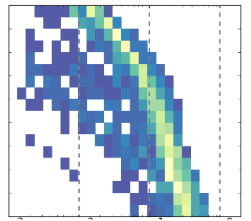

p) ARPEGE-HR

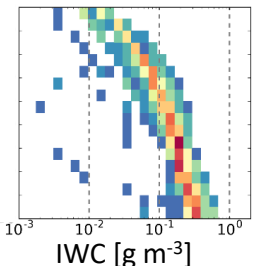

d) LMDZ-LR

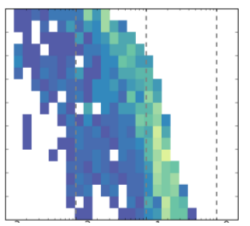

i) LMDZ-LR

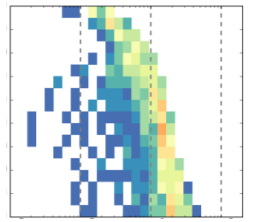

m) LMDZ-LR

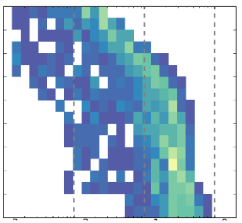

q) LMDZ-LR

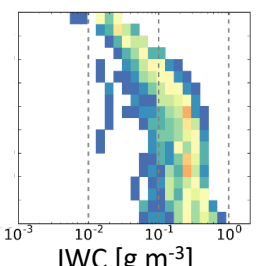

e) LMDZ-HR

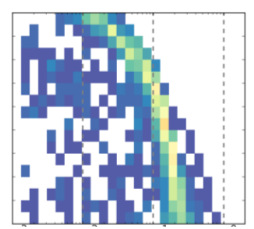

j) LMDZ-HR

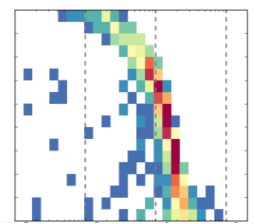

n) LMDZ-HR

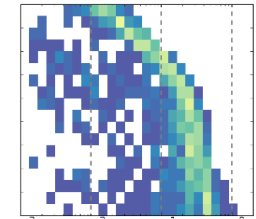

r) LMDZ-HR

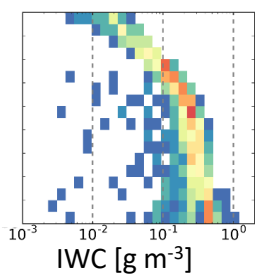

Figure S 5. Bi-variate histograms of Pressure vs. Ice water content (IWC) for F6. a) RASTA (radar observations) and f) RALI (radar + lidar observations). b-e) all model data along the flight trajectory for IWC derived from model "potential" IWC; g-j) as in b-e) but with a mask applied to where observations occur; $\mathrm{k}-\mathrm{n}$ ) all model data along the flight trajectory for model "maximum" IWC to account for supercooled liquid; o-r) as in k-n) but with a mask applied to where observations occur. b,g,k,o) for ARPEGE-LR hindcast; c,h,l,p) ARPEGE-HR hindcast; d,i,m,q) LMDZ-LR hindcast and e,j,n,r) LMDZ-HR hindcast. The hindcasts were initiated at 00 UTC 1 October 2016. The flight occurred from 09:00-11:00 UTC 2 October 2016 and the models are averages from 09:00 UTC and 12:00 UTC 2 October 2016 (T+33 h and $\mathrm{T}+36 \mathrm{~h}$, respectively). 
a) LR (IWC)

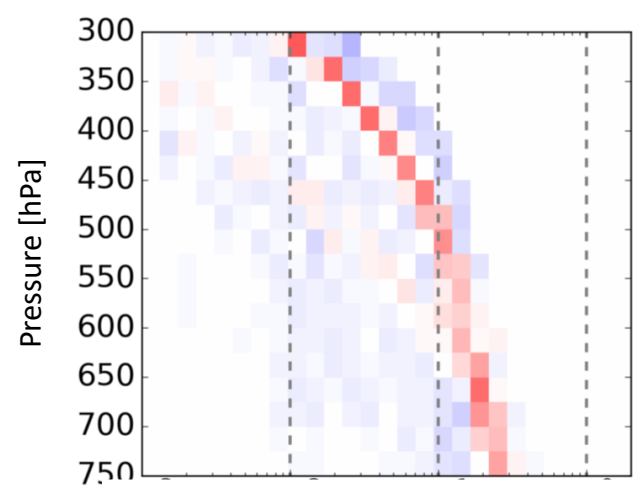

c) $L R(I W C+L W C)$

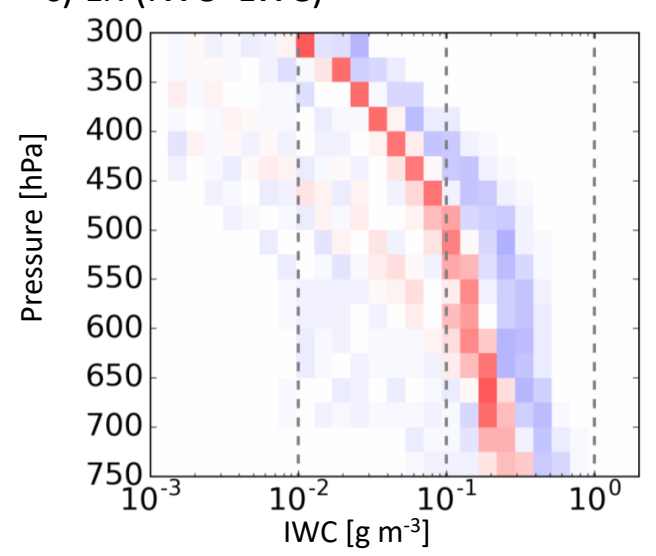

b) HR (IWC)

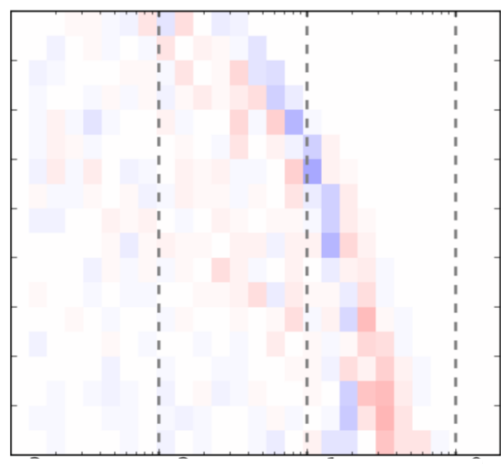

d) HR (IWC+LWC)

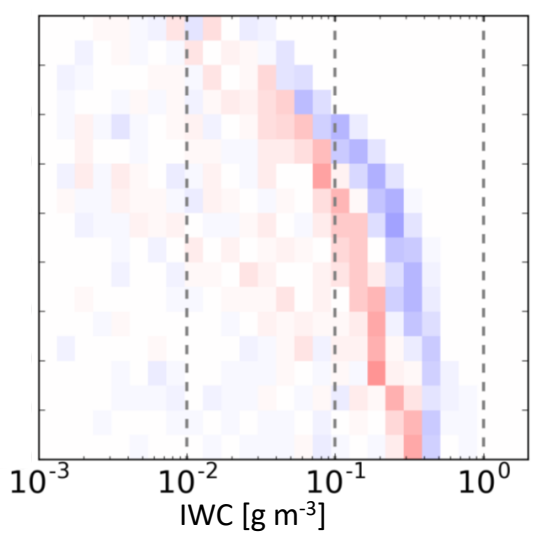

0.020

0.016

0.012

0.008

0.004

0.000

$-0.004$

$-0.008$

$-0.012$

$-0.016$

$-0.020$

Figure S 6. Bi-variate histograms of Pressure vs. Ice water content (IWC) of the differences between ARPEGE and LMDZ along the F6 trajectory. Red values represent ARPEGE being larger than LMDZ, and vice versa for the blue. a,b) "potential” IWC, c,d) "maximum” IWC; a,c) LR configurations and b,d) HR configurations. All simulations are from 00 UTC 1 October 2016 hindcasts and at 09:00 UTC and 12:00 UTC 2 October 2016 ( $\mathrm{T}+33 \mathrm{~h}$ and $\mathrm{T}+36 \mathrm{~h}$, respectively). 
a) Observations

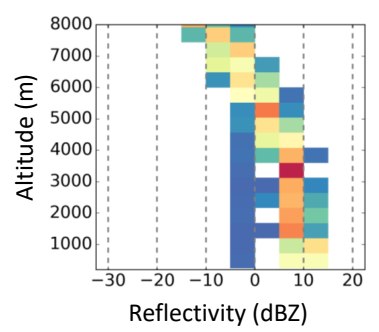

b) ARPEGE-LR

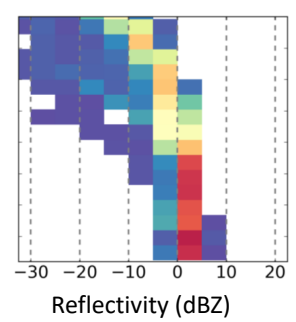

c) ARPEGE-HR

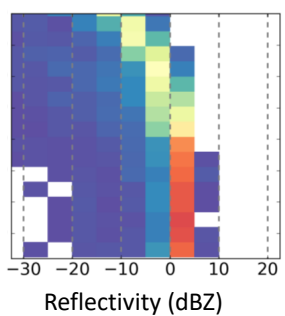

d) LMDZ-LR

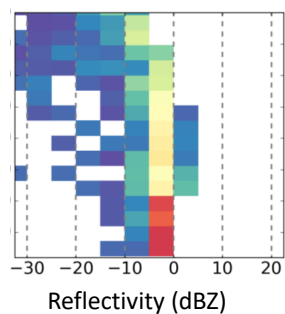

e) LMDZ-HR

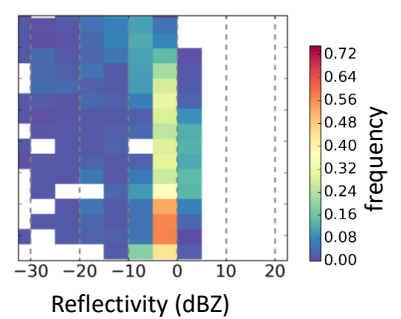

Figure S 7. Contour Altitude Frequency Diagrams (CFADs) of Radar Reflectivity for F6 a) Observations; b) ARPEGE-LR; c) ARPEGE-HR; d) LMDZ-LR; and e) LMDZ-HR. The hindcasts were initiated at 00 UTC 1 October 2016. The flight occurred from 09:00-11:00 UTC 2 October 2016 and the models are averages from 09:00 UTC and 12:00 UTC 2 October $2016(\mathrm{~T}+33 \mathrm{~h}$ and T+36 h, respectively).

A-Train 2016/10/02: Cloudsat and CALIPSO
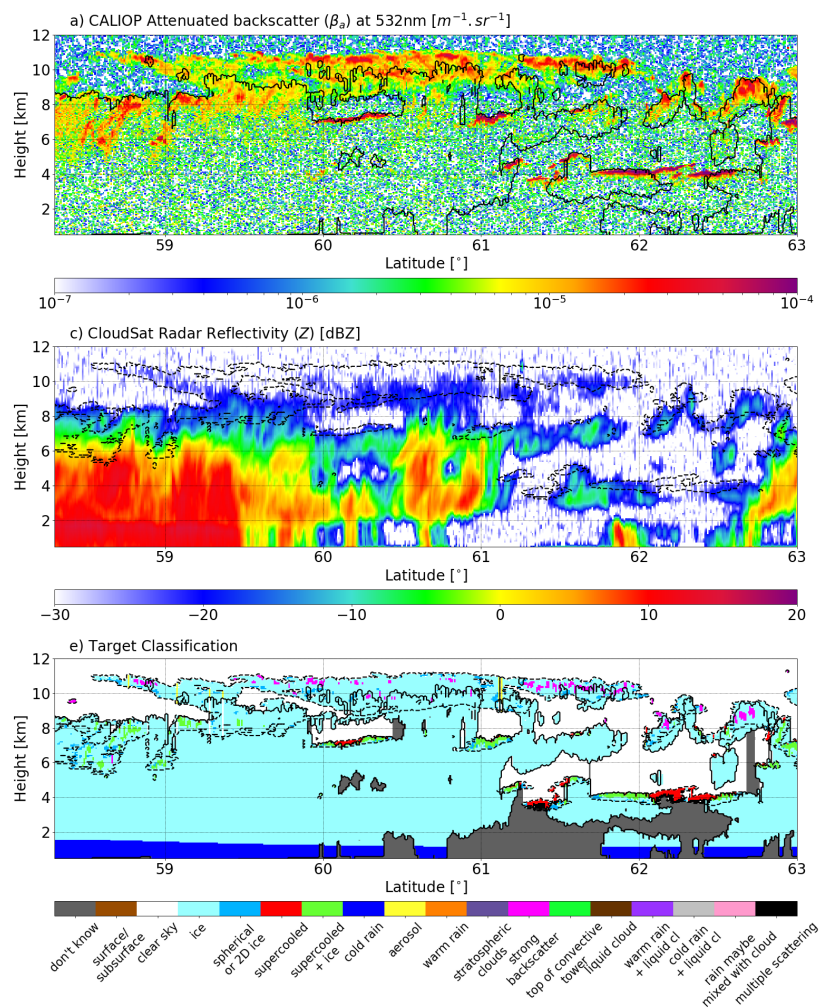

RALI 2016/10/02: RASTA and LNG

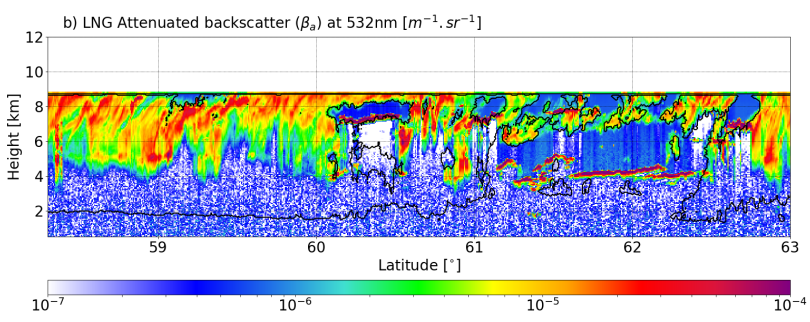

12 d) RASTA Radar Reflectivity (Z) [dBZ]
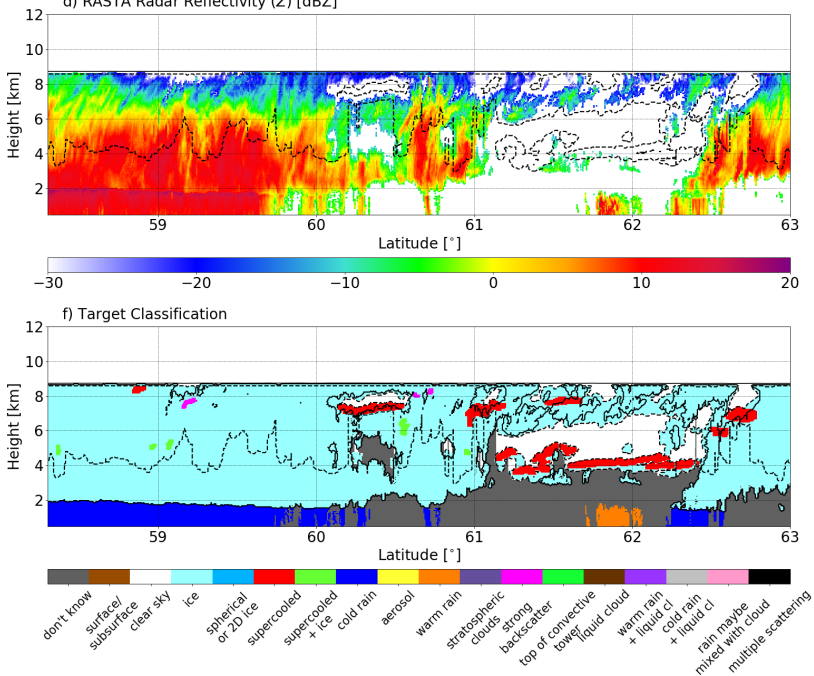

Figure S 8. Co-located F7 and A-Train measurements as a function of latitude on 2 October 2016. (a),(b) show the lidar attenuated backscatter at 532nm for CALIPSO and LNG respectively. (c),(d) correspond to the CloudSat and RASTA reflectivity. (e), (f) illustrate the synergistic radar-lidar mask (DARDAR on the left-hand side). Black isolines show the contours of the radar measurements when looking at the lidar data and the contours of the lidar measurements for the radar reflectivity. 